\title{
Challenges on dental education post COVID-19
}

\begin{abstract}
Ramón Fuentes-Fernández ${ }^{1}$, Yanela Aravena-Rivas ${ }^{2 *}$
1. Departamento de Odontología Integral Adultos, Facultad de Odontología, Universidad de La Frontera, Temuco, Chile.

2. Centro de Investigación en Epidemiología, Economía y Salud Pública Oral (CIEESPO), Facultad de Odontología, Universidad de La Frontera, Temuco, Chile.

*Correspondencia a: Yanela Aravena-Rivas | Address: Avda. Francisco Salazar 1145, Temuco, Chile. | E-mail: yanela.aravena@ufrontera.cl | Phone: +56 452596627

Trabajo recibido 31/08/2020

Aprobado para su publicación 18/10/2020

COVID-19 pandemic caused by SARS-CoV-2 has changed our lives ever since the outbreak. Countries have had to implement quarantines and pause non-essential activities, as well as try to minimise its effects(1). Universities have also been affected by this novel situation. Dental Schools have had to adapt their educational methods in undergraduate and postgraduate education. The experience gained during these past few months allows us to make some reflections regarding the challenges faced by dental education institutions. First, It is our belief that there was an overreaction regarding the dental profession and its effect on the pandemic. The proficiency in the use of personal protective equipment by dentists and their staff, and their ability to implement new requirements in accordance with the pandemic development was underestimated. It becomes evident that the institutions speaking on behalf of the dental profession must analyse the repercussions of their actions in order to provide a more accurate representation. This becomes particularly important when we consider the likely increase of the oral health population needs as a result of the decrease in access to dental services ${ }^{(2)}$, and the increase of social inequalities in health ${ }^{(3)}$. Regarding dental education, universities' greatest challenge is to safely return to clinical teaching. In this sense, We propose the following elements to be considered:

- To adapt, implement, comply, and supervise previous and current legislation and regulation of dental care provision ${ }^{(4)}$.

- To reflect on the need to create a thoughtful communication plan to combat current myths about the coronavirus disease that have likely permeated to the dental education community.

- To implement mental health containment strategies for the dental community members, particularly at the beginning of dental courses.

- To understand that the learning curve of the new applied protocols will be different for students, academics, university staff, and clinical staff.

- To face that it is likely that dental procedures will be resumed gradually. This will increase implementation complexity. Proper planning and supervision will be fundamental in the aforementioned transition.

- To address the issue that clinical procedures will be slower due to the new dental guidelines. Universities will have to consider adapting their traditional clinical requisites for approval. How to handle this situation is of great importance due to its legal, academic, and clinical implications.

- To assess which elements of clinical dental education can be replaced by simulations or other pre-clinical activities.

- To strengthen the use of methodologies which have increased their presence in the pandemic context such as teledentistry and contactability protocols.

- To support the use of virtual platforms in dental education as a valid method for dental education, as these virtual education tools are here to stay.

- To inspect dental services adjoined to internship programmes to ensure their compliance with dental protocols. In cases where dental services struggle, the university should provide help to reach the established standards.

Finally, We emphasize that these elements, are necessary to provide safety to our dental community. As health professionals, we are moved by the oral health of our patients, but we cannot forget to take care of the health of our community. Without question, dentistry will emerge stronger as a result of the COVID-19 pandemic.
\end{abstract}

\section{References}

1. Nicola M, Alsafi Z, Sohrabi C, Kerwan A, Al-Jabir A, losifidis C, et al. The socioeconomic implications of the coronavirus pandemic (COVID-19): A review. Int J Surg. 2020;78:185-93.

2. Muñoz A, Cornejo M. La situación de la odontología en Chile. [citado 28 octubre 2020] Disponible en: https://la.dental-tribune.com/news/la-situacion-de-la-odontologia-en-chile/
3. Marmot M. Society and the slow burn of inequality. Lancet. 2020;395:1413-4. 4. Fuentes $\mathrm{R}$, Zaror $\mathrm{C}$, Huanquilef $\mathrm{M}$. Legislación y normas atingentes a la atención odontológica y el COVID-19. Una perspectiva desde las clínicas universitarias. Int J Odontostomat. 2020;14:481-8. 